\title{
Comparison of Minimally Invasive Direct Coronary Artery Bypass and Percutaneous Coronary Intervention Using Second-Generation Drug-Eluting Stents for Coronary Artery Disease - Propensity Score-Matched Analysis -
}

\author{
Wonsuk Choi, MD; Hyoung Woo Chang, MD, PhD; Si-Hyuck Kang, MD; \\ Chang-Hwan Yoon, MD, PhD; Young-Seok Cho, MD, PhD; Tae-Jin Youn, MD, PhD; \\ In-Ho Chae, MD, PhD; Dong Jung Kim, MD; Jun Sung Kim, MD; Kay-Hyun Park, MD, PhD; \\ Hyo-Soo Kim, MD, PhD; Cheong Lim, MD, PhD; Jung-Won Suh, MD, PhD
}

Background: Some studies comparing minimally invasive direct coronary artery bypass (MIDCAB) and percutaneous coronary intervention ( $\mathrm{PCl}$ ) have reported MIDCAB's superiority, but they did not investigate contemporary $\mathrm{PCl}$ with newer generation drugeluting stents (DES). We compared clinical outcomes after MIDCAB with previously reported outcomes after PCI with second-generation DES.

Methods and Results: We retrospectively reviewed the records of patients treated with MIDCAB. Baseline characteristics and clinical outcomes after MIDCAB were compared with those for left anterior descending artery disease treated via PCl. The primary outcomes were major adverse cardiovascular and cerebrovascular events (MACCE), a composite of cardiovascular death, non-fatal myocardial infarction, ischemic stroke, and target vessel revascularization (TVR). A propensity score-matching (PSM) analysis was conducted to adjust for between-group differences in baseline characteristics. We analyzed 77 patients treated with MIDCAB and 2,206 treated with PCI. The MIDCAB group was older and had more severe coronary disease and a higher incidence of left ventricular dysfunction. Over a 3-year follow-up, the PCI group had favorable MACCE outcomes. After PSM, there were no betweengroup differences in MACCE (MIDCAB, $15.6 \%$ vs. $\mathrm{PCl}, 23.4 \%$; hazard ratio $[\mathrm{HR}], 0.80 ; 95 \% \mathrm{Cl}: 0.38-1.68, \mathrm{P}=0.548$ ) or TVR (MIDCAB, $2.6 \%$ vs. $\mathrm{PCl}, 5.2 \%$; HR, 0.51; $95 \% \mathrm{Cl}: 0.10-3.09, \mathrm{P}=0.509$ ).

Conclusions: Clinical outcomes were similar between MIDCAB and PCI using second-generation DES over 3 years of follow-up.

Key Words: Drug-eluting stent; Minimally invasive direct coronary artery bypass; Percutaneous coronary intervention

M inimally invasive direct coronary artery bypass (MIDCAB) is a method of coronary artery bypass graft $(\mathrm{CABG})$ surgery that is performed without a median sternotomy. It has similar clinical outcomes but many advantages over conventional CABG, including shorter intensive care unit (ICU) stay, fewer wound infections, fewer transfusions, and shorter incision length. ${ }^{1-3}$ In addition to these advantages, MIDCAB is a reasonable treatment option for proximal left anterior descending artery (LAD) stenosis, especially in patients who are not suitable candidates for percutaneous coronary intervention (PCI). ${ }^{4}$

Received December 11, 2018; revised manuscript received March 24, 2019; accepted April 9, 2019; J-STAGE Advance Publication released online May 24, 2019 Time for primary review: 29 days

Cardiovascular Center, Seoul National University Bundang Hospital, Seongnam (W.C., S.-H.K., C.-H.Y., Y.-S.C., T.-J.Y., I.-H.C., J.-W.S.); Division of Cardiology, Department of Internal Medicine, Seoul National University College of Medicine, Seoul (W.C., S.-H.K., C.-H.Y., Y.-S.C., T.-J.Y., I.-H.C., H.-S.K., J.-W.S.); Department of Thoracic and Cardiovascular Surgery, Seoul National University Bundang Hospital, Seongnam (H.W.C., D.J.K., J.S.K., K.-H.P., C.L.); and Cardiovascular Center, Seoul National University Hospital, Seoul (H.-S.K.), South Korea

The first two authors contributed equally to this work (W.C., H.W.C.).

Mailing address: Cheong Lim, MD, PhD, Associate Professor, Department of Thoracic and Cardiovascular Surgery, Seoul National University Bundang Hospital, 82 Gumiro 173, Bundang, Seongnam, Republic of Korea. E-mail: mluemoon@snubh.org or Jung-Won Suh, MD, PhD, Professor, Division of Cardiology, Cardiovascular Center, Seoul National University Bundang Hospital College of Medicine, Seoul National University, 82 Gumiro 173, Bundang, Seongnam, Republic of Korea. E-mail: suhjw1@ gmail.com

ISSN-1346-9843 All rights are reserved to the Japanese Circulation Society. For permissions, please e-mail: cj@j-circ.or.jp 


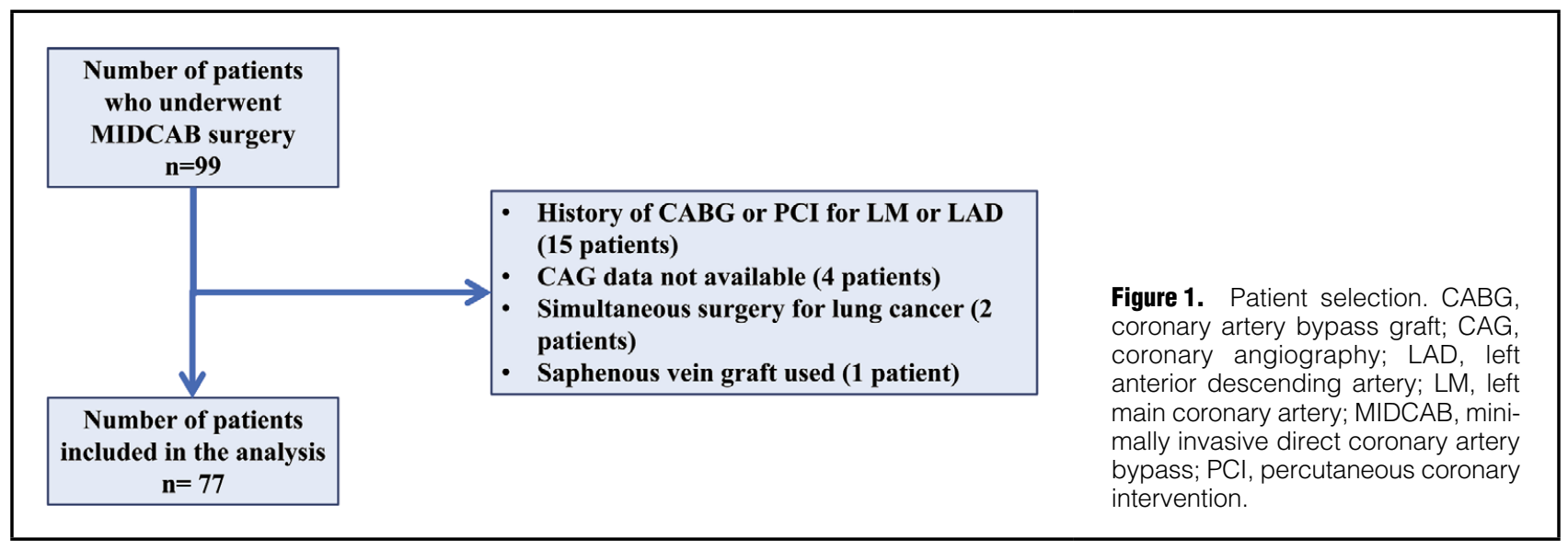

Several studies have compared MIDCAB to PCI for the treatment of proximal LAD stenosis and demonstrated concordant outcomes. Myocardial infarction (MI), allcause death, and cardiovascular death rates were not different between the 2 treatment options, whereas MIDCAB had favorable results compared with PCI in terms of target vessel revascularization (TVR). ${ }^{\text {5-12 }}$

With newer generation drug-eluting stents (DES), however, the in-stent restenosis (ISR) rate of coronary stents decreased from $20 \%$ in the bare metal stent (BMS) era to $<10 \%$ in the second-generation DES era. ${ }^{13}$ Nevertheless, most randomized controlled trials (RCT) that compared PCI and MIDCAB were conducted using BMS or firstgeneration DES during the early 2000s. ${ }^{5-12}$ Furthermore, in the contemporary clinical environment with patients preferring non-surgical options, the possibility of conducting randomized controlled studies that compare PCI and MIDCAB is limited. ${ }^{14,15}$

The development of hybrid coronary revascularization has led to a steady rise in the occurrence of these complicated conditions. This procedure treats multi-vessel disease through a combined approach that includes surgery and PCI. Specifically, the LAD is treated using MIDCAB, while other arteries, including the left circumflex artery (LCX) and right coronary artery (RCA), are treated percutaneously. Several studies have compared $\mathrm{CABG}$ and MIDCAB for multi-vessel disease but, to our knowledge, there have been no prior reports on the hybrid approach vs. PCI in multi-vessel disease. ${ }^{16,17}$

The aim of this study was therefore to investigate outcomes after MIDCAB in patients with either proximal LAD stenosis or multi-vessel disease who were treated with hybrid coronary revascularization at a single center. We used a propensity score model to compare the clinical outcomes after MIDCAB with those of a historical control group treated with PCI using second-generation DES.

\section{Methods}

\section{Patient Selection and Data Collection}

This study was approved by the Institutional Review Board of Seoul National University Bundang Hospital. The requirement for obtaining informed consent was waived due to the retrospective design of the study.

Between September 2007 and June 2017, 99 consecutive patients underwent MIDCAB at Seoul National University
Bundang Hospital. In patients with complex coronary artery disease (CAD), the decision whether to perform PCI, hybrid therapy, or CABG through median sternotomy was made after discussion with the heart team, which consisted of interventional cardiologists, cardiac imaging specialists and thoracic surgeons. Patients were informed of the possible treatment options by the cardiologist and thoracic surgeon of the heart team. The final decision was made by the responsible doctor and patient after consideration of the patient's will and discussion with the heart team.

MIDCAB was performed through a left anterolateral thoracotomy in the 4th intercostal space. The left internal thoracic artery (LITA) was harvested using the skeletonization technique under direct vision. The anastomosis between in situ LITA and LAD (or diagonal branch) was performed using 8-0 polypropylene continuous sutures in an end-to-side manner. The intact anastomosis was confirmed on transit-time flowmetry before closing the chest.

Patients who underwent simultaneous surgery for lung cancer (2 patients), those with a prior history of CABG or PCI to the left main coronary artery (LM) or LAD (15 patients), those whose coronary angiography (CAG) data before surgery were not available (4 patients), or those with a saphenous vein graft for an I-anastomosis (1 patient) were excluded from the study (Figure 1).

The primary endpoint of the study was major adverse cardiovascular and cerebrovascular events (MACCE), which was a composite of all-cause death including cardiovascular death, non-fatal MI, ischemic stroke, and TVR. Secondary endpoints included occurrence of any of the MACCE components during the follow-up period. Clinical events were defined according to the Academic Research Consortium (ARC) recommendations. Peri-procedural MI after PCI was defined as an increase in the creatine kinase muscle/ brain (CK-MB) fraction, or troponin-T or $-\mathrm{I}>3$-fold the upper limit of normal. Peri-procedural MI after CABG was defined as an increase in the CK-MB fraction, or troponin-T or -I $>5$-fold the upper limit of normal in conjunction with any of the following: new pathologic $\mathrm{Q}$ waves or left bundle branch block (LBBB), a new native or graft vessel occlusion, or imaging evidence of a loss of viable myocardium. ${ }^{18}$ Spontaneous MI was defined as clinical signs of MI combined with an increase in the CK-MB fraction or troponin-T or troponin-I above the upper limit of normal. ${ }^{19}$ All deaths were considered cardiac unless a definite non-cardiac cause could be established. TVR in this 
Table 1. Baseline Patient Characteristics vs. Propensity Score Matching Status

\begin{tabular}{|c|c|c|c|c|c|c|}
\hline & \multicolumn{3}{|c|}{ Before propensity score matching } & \multicolumn{3}{|c|}{ After propensity score matching } \\
\hline & $\begin{array}{c}\text { MIDCAB patients } \\
(n=77)\end{array}$ & $\begin{array}{c}\text { PCI patients } \\
(n=2,206)\end{array}$ & P-value & $\begin{array}{c}\text { MIDCAB patients } \\
(\mathrm{n}=77)\end{array}$ & $\begin{array}{c}\text { PCI patients } \\
(n=77)\end{array}$ & P-value \\
\hline Sex (men) & $59(76.6)$ & $1,450(65.7)$ & 0.047 & $59(76.6)$ & $63(81.8)$ & 0.427 \\
\hline Age (years) & $68.6 \pm 11.6$ & $62.9 \pm 11.1$ & $<0.001$ & $68.6 \pm 11.6$ & $67.9 \pm 9.2$ & 0.700 \\
\hline BMI $\left(\mathbf{k g} / \mathrm{m}^{2}\right)$ & $23.9 \pm 3.1$ & $24.0 \pm 5.0$ & 0.949 & $23.9 \pm 3.1$ & $23.9 \pm 3.5$ & 0.964 \\
\hline Smoking status & & & 0.005 & & & 0.917 \\
\hline Non-smoker & $37(47.4)$ & 1,107 (50.2) & & $37(47.4)$ & $38(49.4)$ & \\
\hline Ex-smoker (1 month) & $26(33.3)$ & $438(19.9)$ & & $26(33.3)$ & $23(29.9)$ & \\
\hline Current smoker & $14(19.2)$ & $661(30.0)$ & & $14(19.2)$ & $16(20.8)$ & \\
\hline \multicolumn{7}{|l|}{ Underlying disease } \\
\hline HTN & $51(66.2)$ & $1,487(67.4)$ & 0.829 & $51(66.2)$ & $50(64.9)$ & 0.865 \\
\hline DM & $38(49.4)$ & $691(31.3)$ & 0.001 & $38(49.4)$ & $34(44.2)$ & 0.518 \\
\hline Dyslipidemia & $20(26.0)$ & $1,426(64.6)$ & $<0.001$ & $20(26.0)$ & $23(29.9)$ & 0.590 \\
\hline CVA & $12(15.6)$ & $141(6.4)$ & 0.002 & $12(15.6)$ & $12(15.6)$ & 1.0 \\
\hline CKD & $11(14.3)$ & $61(2.8)$ & $<0.001$ & $11(14.3)$ & $8(10.4)$ & 0.462 \\
\hline COPD & $9(11.7)$ & $58(2.6)$ & $<0.001$ & $9(11.7)$ & $5(6.5)$ & 0.262 \\
\hline LVEF & $54.4 \pm 13.1$ & $51.9 \pm 23.1$ & 0.103 & $54.4 \pm 13.1$ & $57.7 \pm 16.0$ & 0.173 \\
\hline $\mathrm{EF}<40 \%$ & $13(16.5)$ & $111(5.0)$ & $<0.001$ & $13(16.5)$ & $6(7.8)$ & 0.086 \\
\hline \multicolumn{7}{|l|}{ Prior disease } \\
\hline LM & $18(23.4)$ & $35(1.6)$ & $<0.001$ & $18(23.4)$ & $11(14.3)$ & 0.149 \\
\hline LAD & $77(100)$ & $2,206(100)$ & $\mathrm{N} / \mathrm{A}$ & 77 (100) & $77(100)$ & $\mathrm{N} / \mathrm{A}$ \\
\hline LCX & $44(57.1)$ & $803(36.4)$ & $<0.001$ & $44(57.1)$ & $48(62.3)$ & 0.511 \\
\hline $\mathrm{RCA}$ & $40(51.9)$ & $752(34.1)$ & 0.001 & $40(51.9)$ & $43(55.8)$ & 0.628 \\
\hline Prior PCl & $19(24.7)$ & $120(5.4)$ & $<0.001$ & $19(24.7)$ & $16(20.8)$ & 0.564 \\
\hline Сто & $23(29.9)$ & $206(9.3)$ & $<0.001$ & $23(29.9)$ & $25(32.5)$ & 0.728 \\
\hline SYNTAX I score & $26.0 \pm 10.5$ & $13.3 \pm 7.7$ & $<0.001$ & $26.0 \pm 10.5$ & $25.4 \pm 9.3$ & 0.715 \\
\hline Clinical diagnosis & & & $<0.001$ & & & 0.388 \\
\hline Silent ischemia & $18(23.4)$ & $97(4.4)$ & & $18(23.4)$ & $18(23.4)$ & \\
\hline Stable angina & $13(16.9)$ & $685(31.1)$ & & $13(16.9)$ & $25(32.5)$ & \\
\hline Unstable angina & $32(41.6)$ & 866 (39.3) & & $32(41.6)$ & $26(33.8)$ & \\
\hline NSTEMI & $8(10.4)$ & 335 (15.2) & & $8(10.4)$ & $15(19.5)$ & \\
\hline STEMI & $6(7.8)$ & $223(10.1)$ & & $6(7.8)$ & $5(6.5)$ & \\
\hline \multicolumn{7}{|l|}{ Medication } \\
\hline Aspirin & $76(98.7)$ & 2,191 (99.3) & 0.522 & $76(98.7)$ & $77(100.0)$ & 0.316 \\
\hline Clopidogrel & $66(85.7)$ & $2,194(99.5)$ & $<0.001$ & $66(85.7)$ & $77(100.0)$ & 0.001 \\
\hline Cilostazol & $1(1.3)$ & $1,054(47.8)$ & $<0.001$ & $1(1.3)$ & $40(51.9)$ & $<0.001$ \\
\hline ACEI or ARB & $28(36.4)$ & $1,447(65.6)$ & $<0.001$ & $28(36.4)$ & $30(39.0)$ & 0.739 \\
\hline$\beta$-blocker & $43(55.8)$ & $1,488(67.5)$ & 0.033 & $43(55.8)$ & $48(62.3)$ & 0.413 \\
\hline ССВ & $29(37.7)$ & 440 (19.9) & $<0.001$ & $29(37.7)$ & $26(33.8)$ & 0.614 \\
\hline Nitrates & $2(2.6)$ & $1,447(65.6)$ & $<0.001$ & $2(2.6)$ & $30(39.0)$ & $<0.001$ \\
\hline HMG-CoA reductase inhibitor & $62(80.5)$ & $1,889(85.6)$ & 0.211 & $62(80.5)$ & $61(79.2)$ & 0.841 \\
\hline
\end{tabular}

Data given as $\mathrm{n}(\%)$ or mean $\pm \mathrm{SD}$. ACEI, angiotensin-converting enzyme inhibitor; ARB, angiotensin II receptor blocker; BMI, body mass index; CCB, calcium-channel blocker; CKD, chronic kidney disease; COPD, chronic obstructive pulmonary disease; CTO, chronic total occlusion; CVA, cerebrovascular accident; DM, diabetes mellitus; EF, ejection fraction; HMG-CoA, 3-Hydroxy-3-methylglutaryl-Coenzyme-A; HTN, hypertension; LAD, left anterior descending coronary artery; LCX, left circumflex artery; LM, left main coronary artery; LVEF, left ventricula ejection fraction; MIDCAB, minimally invasive direct coronary artery bypass; N/A, not available; NSTEMI, non-ST elevation myocardial infarction; $\mathrm{PCl}$, percutaneous coronary intervention; RCA, right coronary artery; STEMI, ST elevation myocardial infarction; SYNTAX, Synergy between $\mathrm{PCl}$ with Taxus and Cardiac Surgery.

study was confined to the LAD. TVR events that occurred in the LCX or RCA were excluded from analysis.

Baseline clinical, echocardiographic, and angiographic data were obtained. CAG obtained before MIDCAB was reviewed. Angiographic findings including extent of disease, history of prior PCI, and presence of chronic total occlusion (CTO) were obtained. The Synergy between PCI with Taxus and Cardiac Surgery (SYNTAX) score was also calculated. Follow-up data were collected on review of the medical records or via telephone questionnaires.

\section{Historical PCI Group Comparison}

Baseline characteristics and clinical outcomes data from patients who underwent MIDCAB were compared with patient data from the Harmonizing Optimal Strategy for Treatment of Coronary Artery Stenosis-Safety \& Effectiveness of Drug-Eluting Stents \& Anti-platelet Regimen (HOST-ASSURE) trial. ${ }^{20}$ That multi-center clinical trial 


\begin{tabular}{|c|c|c|c|c|c|c|}
\hline & \multicolumn{3}{|c|}{ Before propensity score matching } & \multicolumn{3}{|c|}{ After propensity score matching } \\
\hline & $\begin{array}{c}\text { MIDCAB patients } \\
(n=77)\end{array}$ & $\begin{array}{c}\mathrm{PCl} \text { patients } \\
(\mathrm{n}=2,206)\end{array}$ & P-value & $\begin{array}{c}\text { MIDCAB patients } \\
(\mathrm{n}=77)\end{array}$ & $\begin{array}{c}\text { PCI patients } \\
(\mathrm{n}=77)\end{array}$ & P-value \\
\hline Follow-up (days) ${ }^{\dagger}$ & $891.5(899)$ & $1,092(65)$ & 0.003 & $891.5(899)$ & $861.5(396.3)$ & 0.684 \\
\hline \multicolumn{7}{|l|}{ Follow-up results } \\
\hline End of follow-up without MACCE & $56(72.7)$ & $1,863(84.5)$ & & $56(72.7)$ & $56(72.7)$ & \\
\hline Lost to follow-up & $8(10.4)$ & $120(5.4)$ & & $8(10.4)$ & $4(5.2)$ & \\
\hline MACCE & $13(16.9)$ & $223(10.1)$ & 0.031 & $13(16.9)$ & $17(22.1)$ & 0.391 \\
\hline Cardiac death & $6(7.8)$ & $44(2.0)$ & 0.002 & $6(7.8)$ & $7(9.1)$ & 0.541 \\
\hline Non-cardiac death & $3(3.9)$ & $26(1.2)$ & 0.014 & $3(3.9)$ & $2(2.6)$ & 0.510 \\
\hline MI & $2(2.6)$ & $30(1.4)$ & 0.254 & $2(2.6)$ & $3(3.9)$ & 0.642 \\
\hline CVA & $0(0)$ & $26(1.2)$ & 0.389 & $0(0)$ & $1(1.3)$ & 0.314 \\
\hline TVR & $2(2.6)$ & $97(4.4)$ & 0.632 & $2(2.6)$ & $4(5.2)$ & 0.436 \\
\hline Stent thrombosis & $0(0.0)$ & $7(0.3)$ & 1.0 & $0(0.0)$ & $1(1.3)$ & 1.0 \\
\hline
\end{tabular}

Data given as $\mathrm{n}(\%)$ or ${ }^{\mathrm{t}}$ median (IQR). MACCE, major adverse cardiovascular and cerebrovascular events; MI, myocardial infarction; TVR, target vessel revascularization. Other abbreviations as in Table 1.

enrolled 3,784 patients from 50 centers in Korea. The patients were enrolled from June 2010 to November 2011. They were treated with either the Promus Element ${ }^{\circledR}$ everolimus-eluting stent (EES; Boston Scientific, Natick, MA, USA) or the Endeavor Resolute ${ }^{\circledR}$ zotarolimus-eluting stent (ZES; Medtronic, Minneapolis, MN, USA) by randomization. The primary outcome was MACCE, as a composite of cardiovascular death, non-fatal MI, ischemic stroke, and TVR. Anti-platelet therapies were also compared in that study. Triple anti-platelet therapy, including aspirin, clopidogrel, and cilostazol given for 1 month after PCI, was compared with double-dose clopidogrel dual antiplatelet therapy given for 1 month after PCI. The clinical follow-up duration was 36 months after the procedure. Follow-up CAG was recommended to all patients at 13 months after the initial procedure. Patients with a prior history of CABG, prior history of PCI to the LM or LAD, or whose CAG data were not available were excluded from the analysis. Clinical data from 2,206 patients whose LAD were treated with PCI were included and were compared with the MIDCAB group data. Because the follow-up duration in the control group was set to 3 years and the maximum follow-up duration was 1,161 days, the maximum follow-up duration for the study was also set to 1,161 days to accurately compare the clinical outcomes.

\section{Statistical Analysis}

Baseline patient characteristics are presented as n (\%) for the categorical variables and as mean \pm SD for the continuous variables. The categorical variables were analyzed using either the chi-squared or Fisher's exact tests. Continuous data were compared using the unpaired Student's t-test. All-cause death, MACCE, cardiovascular death, and TVR-free curves were created according to the KaplanMeier method and were compared using log rank test. A Cox-proportional hazard model was constructed to evaluate the hazard ratio (HR) for each event in both groups. All reported $\mathrm{P}$-values are 2-tailed, and $\mathrm{P}<0.05$ was considered statistically significant.

The propensity score was derived using a logistic regression model in which the outcome was the log of the odds of undergoing MIDCAB. A regression model was tested using the Hosmer-Lemeshow goodness of fit, and $\mathrm{P}>0.05$ was regarded as an acceptable model. All baseline charac- teristics that varied between the MIDCAB and PCI groups at $\mathrm{P}<0.10$ or that were potentially related to outcome were included in the propensity score model. Although the presence of hypertension was not significant on logistic regression analysis, it was included in the propensity score model. Antiplatelet agents prescribed at the time of discharge were excluded from the propensity score model because they could be directly influenced by the treatment methods. Using a 1:1 greedy nearest neighbor matching algorithm, MIDCAB and PCI patients were matched according to propensity score. After propensity score matching, continuous variables were compared using independent t-test and categorical variables were compared using chi-squared test or Fisher's exact test if the variables were non-parametric.

Statistical analysis was performed using SPSS v20 (IBM, Armonk, NY, USA) and R v3.5.1. (R Development Core team, 2018).

\section{Results}

A total of 77 patients underwent MIDCAB. After diagnostic CAG, surgery was planned for 54 patients $(70.9 \%)$ : MIDCAB alone in 34 patients $(44 \%)$ or hybrid coronary revascularization in 20 patients $(26.9 \%)$. PCI to treat LAD disease was attempted, but subsequently failed in 14 patients $(17.9 \%)$. Their treatment plan was consequently converted to MIDCAB. Eight patients (10.3\%) had intra-abdominal surgery that could not be delayed due to reasons such as colon cancer. One patient $(1.3 \%)$ was allergic to aspirin.

In all 77 patients, the LITA was anastomosed to the LAD. LITA were additionally connected to diagonal branches in 3 patients. The average operation time was $166.2 \pm 48.6 \mathrm{~min}$, and the duration until extubation after surgery was $6.9 \pm 12.2 \mathrm{~h}$. The average ICU stay time was $47.9 \pm 165.3 \mathrm{~h}$, and the average discharge duration after surgery was $10.0 \pm 12.8$ days. The average amount of transfusion during or after surgery was $1.4 \pm 4.7$ units including packed red blood cells, platelets, fresh frozen plasma, or cryoprecipitate. Two patients required transfusion $>10$ units of blood products. These 2 patients received 25 and 32 units of blood products during their surgery.

Data of the MIDCAB group were compared with data of the PCI group from the aforementioned trial. Patients who were treated with MIDCAB were more often men, 

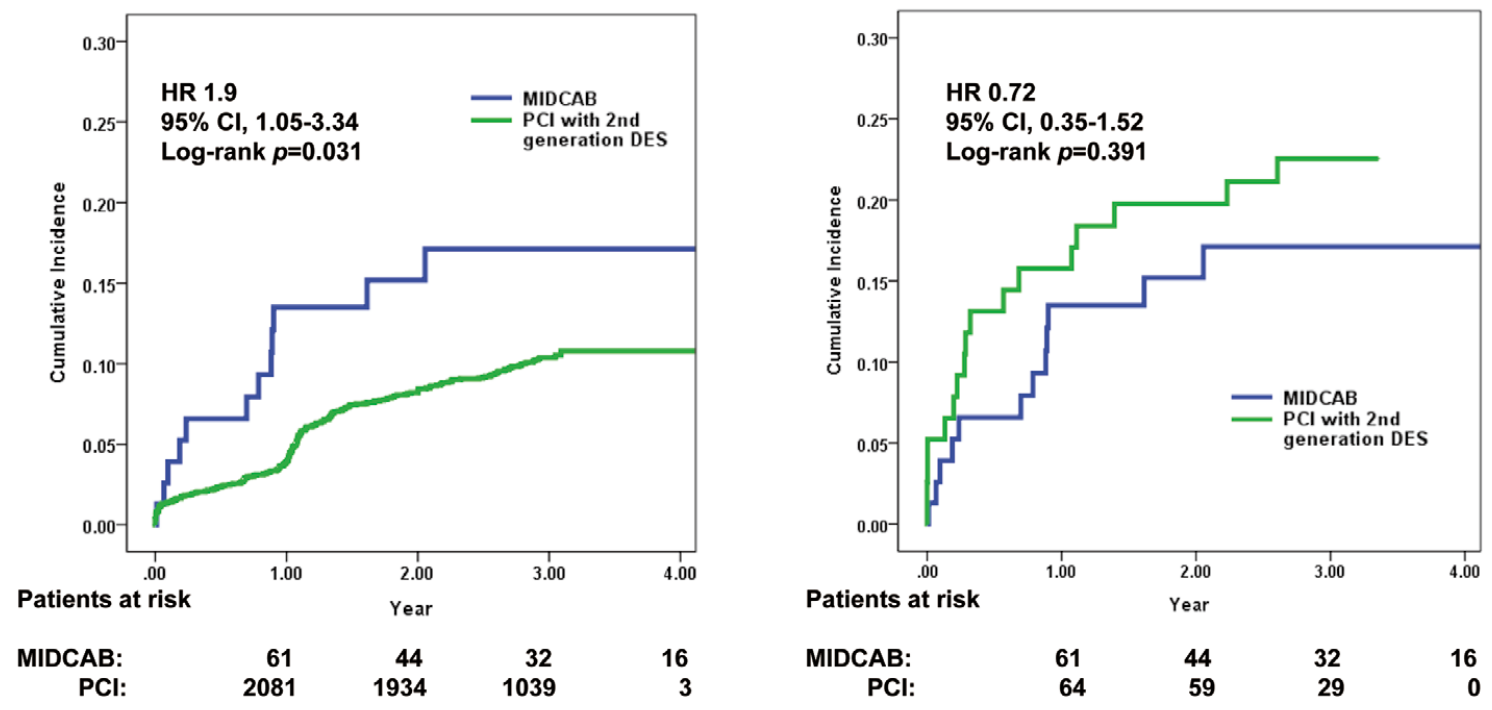

Figure 2. Kaplan-Meier cumulative event curves for major adverse cardiovascular or cerebrovascular events (MACCE) after MIDCAB and PCI with second-generation drug-eluting stents (DES) (Left) before and (Right) after propensity score matching. Other abbreviations as in Figure 1.
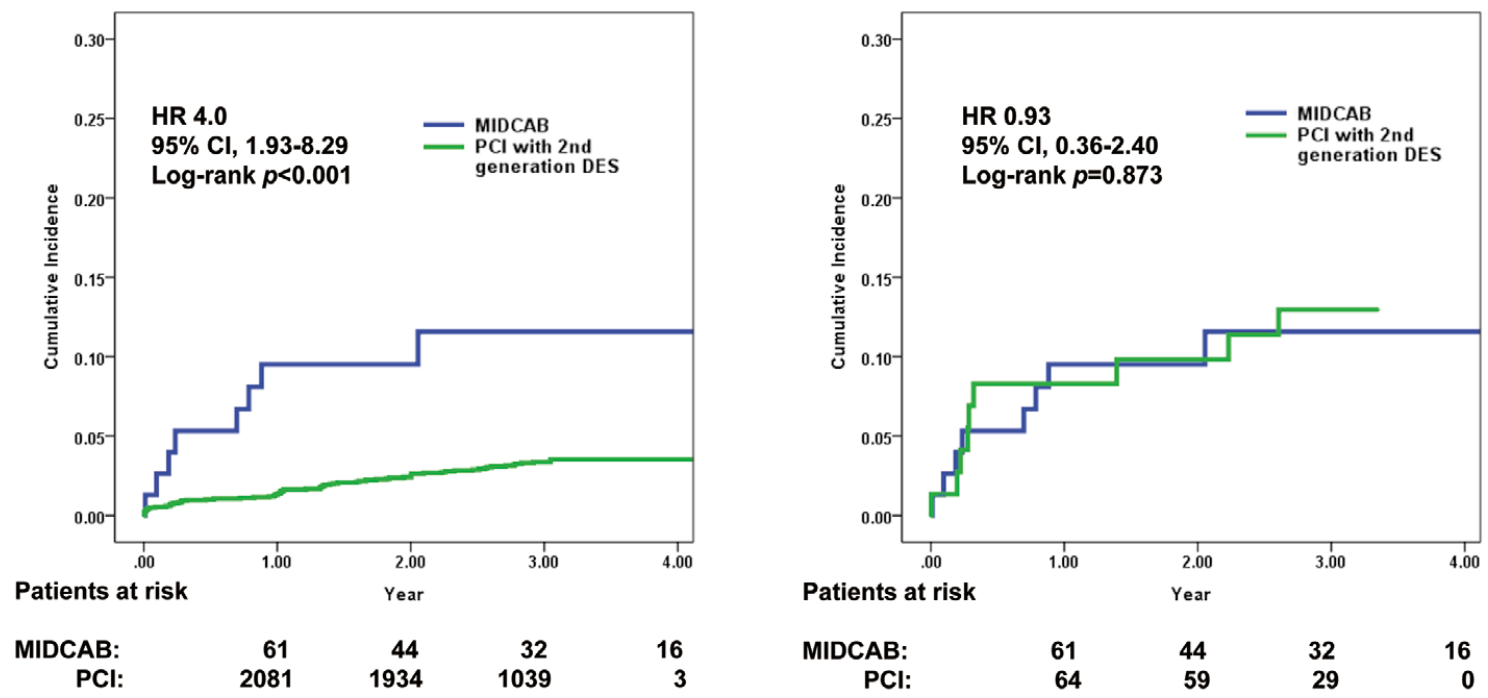

Figure 3. Kaplan-Meier cumulative event curves for all-cause deaths after MIDCAB and PCI with second-generation DES (Left) before and (Right) after propensity score matching. Other abbreviations as in Figures 1,2.

were older, had more severe underlying disease, and had more CTO than those in the PCI group. SYNTAX I score and the proportion of patients with low left ventricular ejection fraction were also significantly higher in the MIDCAB group. Medication prescribed at discharge was significantly different between the 2 treatment groups. Patients in the PCI group were more frequently prescribed clopidogrel, cilostazol, angiotensin-converting enzyme inhibitors (ACEI) or angiotensin II receptor blockers (ARB), $\beta$-blockers, calcium-channel blockers (CCB), and nitrates. PLATelet inhibition and Outcomes (PLATO) bleeding at 1 year of follow-up occurred in 70 patients $(1.9 \%)$. Of these, 8 cases
$(0.02 \%)$ involved life-threatening major bleeding, while 43 cases $(1.1 \%)$ involved major, but not life-threatening bleeding.

After propensity score matching, all baseline characteristics except medication were well-balanced between the 2 groups (Table 1).

The median follow-up period for the MIDCAB patients was 892 days, while that for the PCI patients was 1,092 days ( $\mathrm{P}=0.003$, Table 2). Over the course of the follow-up period, 8 patients were lost to follow-up, 2 had moved to other regions, and the reasons for the other 6 could not be ascertained. After MIDCAB, 9 deaths were reported. In 3 

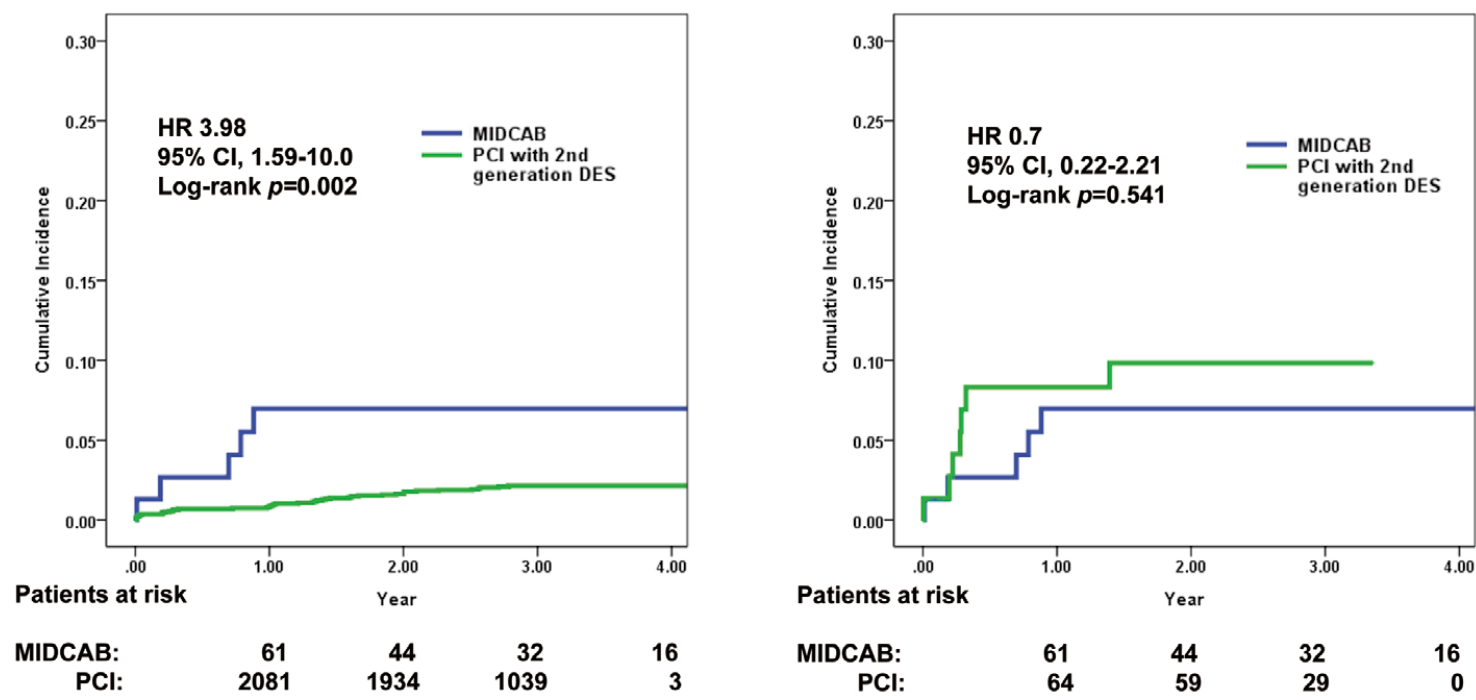

Figure 4. Kaplan-Meier cumulative event curves for incidence of cardiovascular death after MIDCAB and PCI with second-generation DES (Left) before and (Right) after propensity score matching. Other abbreviations as in Figures 1,2.
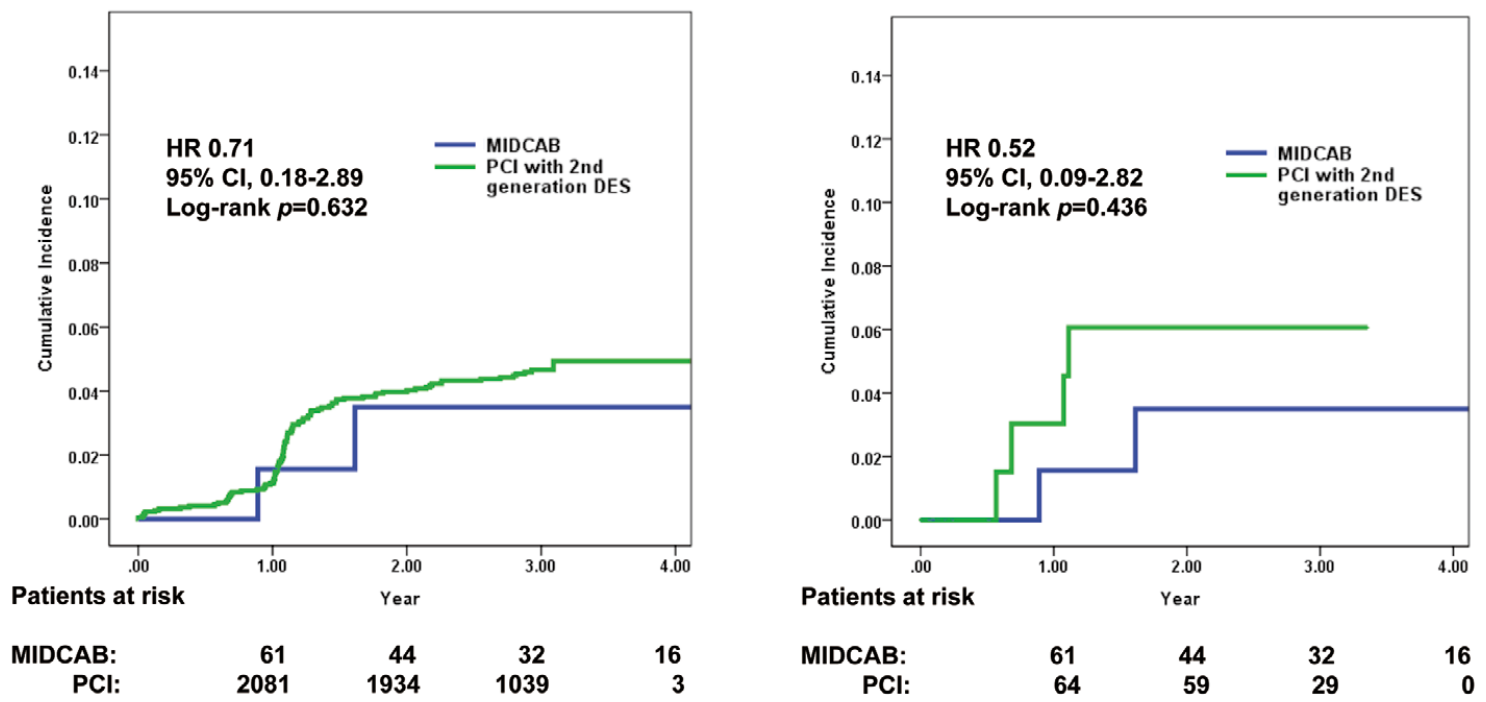

Figure 5. Kaplan-Meier cumulative event curve of target vessel revascularization (TVR) after MIDCAB and PCI with secondgeneration DES (Left) before and (Right) after propensity score matching. Other abbreviations as in Figures 1,2.

such cases, the cause of death was of non-cardiac origin, including septic shock and pneumonia. One patient could not recover from acute MI and died due to multi-organ failure. In the remaining 5 cases, we could not determine the definite cause of death and these cases were regarded as cardiac death.

The cumulative incidence of MACCE was significantly higher in the MIDCAB group before propensity score matching, and this was mainly due to differences in cardiac and non-cardiac mortality. This finding, however, was not significant after propensity score matching (Table 2).

On Kaplan-Meier curve analysis, cumulative MACCE was significantly higher in the MIDCAB group before pro- pensity score matching (MIDCAB, 16.9\% vs. PCI, 10.1\%; HR, 1.9; 95\% CI: 1.05-3.34, $\mathrm{P}=0.031$; Figure 2). After propensity score matching, however, there were no significant differences in MACCE between the MIDCAB and PCI groups. (16.9\% vs $22.1 \%$, HR, 0.72; 95\% CI: 0.35-1.52, $\mathrm{P}=0.391$ ). All-cause death (MIDCAB, $11.7 \%$ vs. PCI, 3.2\%; HR, 4.0; 95\% CI: 1.93-8.29, P<0.001) and cardiac death (MIDCAB, $7.8 \%$ vs. PCI, 2.0\%; HR, 3.98; 95\% CI: 1.59 $10.0, \mathrm{P}=0.002)$ in the MIDCAB group were also higher before matching, although there were no significant differences afterward (MIDCAB, $11.7 \%$ vs. PCI, 11.7\%; HR, 0.93; 95\% CI: $0.36-2.40, \mathrm{P}=0.873$; MIDCAB, $7.8 \%$ vs. PCI, 9.1\%; HR, 0.7; 95\% CI: 0.22-2.21, P=0.541, respec- 
tively; Figures 3,4). TVR was not different between the MIDCAB and PCI groups, both before and after matching $(2.6 \%$ vs. $4.4 \%$; HR, $0.71 ; 95 \%$ CI: $0.18-2.89, \mathrm{P}=0.632$; $2.6 \%$ vs. $5.2 \%$; HR, 0.52 ; $95 \%$ CI: $0.09-2.82, \mathrm{P}=0.436$, respectively; Figure 5).

\section{Discussion}

The present study has demonstrated no significant differences in MACCE, all-cause death, cardiovascular death, or TVR in patients with multi-vessel disease who underwent PCI or MIDCAB in various clinical settings.

Current guidelines for coronary revascularization recommend that multi-vessel disease with proximal LAD lesions should be treated using a heart team approach and should be based on patient preference for therapy. Recent American College of Cardiology/American Heart Association/Society for Cardiovascular Angiography and Interventions guidelines assign CABG a class of IIa based on level of evidence $\mathrm{B}$ recommendations. Level of evidence $\mathrm{B}$ recommendations assign a class level of IIb to patients with isolated proximal LAD disease who undergo LITA grafts during PCI. According to European guidelines, PCI was assigned a class level of IIa based on level of evidence B recommendations, and surgery was assigned a class level of I according to level of evidence A recommendations.,21

These recommendations are primarily supported by several studies that compared PCI with CABG in the treatment of isolated proximal LAD lesions. ${ }^{5-12}$ Although significant differences in mortality and MI rates between PCI and surgery were not observed, TVR rates were concordantly higher in the PCI group. A meta-analysis of 7 RCT that compared PCI with CABG indicated that the odds ratio of TVR was significantly higher for patients who were treated with PCI compared with those treated with MIDCAB during the overall follow-up periods.

Of the 7 studies included in the meta-analysis, however, only 2 evaluated procedures in which DES were used.6,10 One study noted a similar outcome for TVR, while the other study favored MIDCAB. Furthermore, the DES evaluated in the trials were first-generation DES that included sirolimus-eluting stents. In this era of second-generation DES, TVR rates have steadily decreased to $<10 \%{ }^{13}$ In a metaanalysis from another group, the TVR rate was higher for BMS than DES. ${ }^{22}$ Compared with first-generation DES, second-generation DES have lower rates of MI and major adverse cardiovascular events. Second-generation DES, including the EES and ZES-Resolute, were significantly better than paclitaxel-eluting stents with regard to TVR rate. ${ }^{23}$ First-generation DES have durable polymers and thick struts that can cause inflammation and delayed vessel wall healing. ${ }^{24}$ Second-generation stents were developed to address these issues and utilize new biocompatible polymer coatings, less toxic anti-proliferative drugs, and thin struts composed of metal alloys. ${ }^{25,26}$

In the present study, TVR rate, as another set of hard endpoints similar to all-cause mortality or cardiovascular death, was not significantly different between the treatment groups after propensity score matching. Despite the decreased TVR rate after PCI, there are no RCT that have directly compared TVR rates after PCI using second-generation DES with those after MIDCAB. Given that it would have been difficult to conduct an RCT in the current clinical situation, the present well-matched comparison of PCI and CABG could provide clinical clues to potential outcomes after PCI or MIDCAB in patients with multi-vessel CAD.

Drugs prescribed at the time of discharge were significantly different between the 2 groups. Antiplatelet agents, ACEI or ARB, $\beta$-blockers, $\mathrm{CCB}$, and nitrates were more frequently prescribed in the PCI group. We cannot exclude the possibility that the difference in drugs prescribed on discharge could have affected the outcomes. After propensity score matching, however, there was no difference in the prescription rate of $\mathrm{ACEI}$ or $\mathrm{ARB}, \beta$-blocker, or CCB. We did not include antiplatelet agents in the matching because they were directly influenced by the treatment modality itself. After PCI, dual antiplatelet therapy is mandatory unless there is a contraindication, whereas single antiplatelet therapy is standard after CABG. Furthermore, significant differences in antiplatelet agent prescription after PCI vs. surgery were frequently observed in studies that compared the 2 treatment modalities. ${ }^{27-29}$

A significant proportion of patients was prescribed cilostazol, because patients in the control group were extracted from an RCT that compared the outcomes of 1 month of triple antiplatelet therapy with those of 1 month of doubledose clopidogrel therapy. We do not think, however, that the antiplatelet therapy in the present study affected the clinical outcomes in PCI patients because there were no major beneficial or detrimental effects of this treatment strategy compared with conventional dual antiplatelet therapy in a series of studies. ${ }^{30,31}$

Nitrates were excluded because they were more extensively prescribed in the PCI group, and, in most cases, very-short-acting sublingual nitroglycerin was prescribed. Although the prescription rates were significantly different between the 2 groups, we do not think nitrates would influence clinical outcome. ${ }^{32}$

In the present study, we also included patients with multi-vessel CAD. The current guidelines recommend that MIDCAB surgery be performed in cases of isolated proximal LAD stenosis. This surgical procedure, however, is more widely performed as a hybrid coronary revascularization procedure in patients with multi-vessel disease. Multi-vessel disease is an independent risk factor for morbidity and mortality in patients treated with PCI or MIDCAB. The choice of treatment in patients with multi-vessel disease remains controversial despite extensive discussions. In the present study, most had multi-vessel disease. MACCE and TVR rates were not different between the 2 groups.

The potential benefits of MIDCAB result from the longterm patency of the LITA grafted to the LAD. This benefit could be seriously disturbed if there are inadequate connections between the LITA graft and the LAD. For example, myocardial bridging of the LAD poses a challenge in bypass grafting that could adversely affect the outcome. ${ }^{33}$ Additional saphenous vein grafting with an I-anastomosis due to a short LITA graft could be another significant restriction affecting MIDCAB surgery and, potentially, the long-term patency of the graft. ${ }^{34}$ Therefore, patients with additional saphenous vein grafts were excluded from this analysis.

Very late thrombosis and prolonged dual-antiplatelet therapy are possible concerns in the PCI group. Although it was not a striking problem in the present study, very late stent thrombosis is still an important problem for clinicians, because very late stent thrombosis manifests as an acute coronary syndrome with high morbidity and mortality. ${ }^{35}$ To avoid very late thrombosis, a significant proportion of patients was prescribed prolonged dual-antiplatelet therapy, although its clinical benefit has not been well-validated. ${ }^{36,37}$ 


\section{Study Limitations}

This study had several limitations. First, this study was not an RCT; thus, we could not exclude the possibility of selection bias. Patients who underwent MIDCAB surgery included those in whom PCI was not attempted, which could have represented an unmatched confounding factor. We matched the patients as closely as possible, however, based on various clinical and angiographic parameters including SYNTAX I score. Furthermore, all MIDCAB procedures were performed at a single center, whereas the PCI were performed at various hospitals. Given that the MIDCAB patients had severe CAD and multiple underlying diseases, we acquired the control group data from a multi-center trial with a large number of patients to achieve thorough matching. Second, the sample size in this study was small and was inadequate for deriving a firm conclusion. We identified as many patients as possible during the study, from 2007 to 2017, but the number of patients was inadequate for evaluating hard outcomes including allcause death and TVR, given that the annual rates of these events are currently $<5 \%$. Furthermore, MIDCAB surgery and hybrid coronary revascularization are conducted in relatively low-risk patients compared with those who undergo conventional CABG, which makes it difficult to arrive at a firm conclusion. Third, the follow-up durations between the 2 treatment groups were different, although we sought to evaluate several outcomes at the 3-year follow-up point. Because follow-up duration was significantly different between the treatment groups, we were limited to KaplanMeier statistical analysis.

\section{Conclusions}

PCI for LAD using second-generation DES is similar to MIDCAB in terms of MACCE at 3-year follow-up. PCI is a good treatment modality for patients who are suitable candidates for PCI. We should always consider MIDCAB, however, as a potential option for patients with CAD, especially when PCI is deemed difficult and a patient has multiple comorbidities. Further large-scale RCT comparing $\mathrm{MIDCAB}$ and $\mathrm{PCI}$ are warranted to make a firm conclusion.

\section{Disclosures}

The authors declare no conflicts of interest.

\section{Grants}

This work is supported by a grant from the SNUBH Research Fund (04-2012-001).

\section{References}

1. Rogers CA, Pike K, Angelini GD, Reeves BC, Glauber M, Ferrarini M, et al. An open randomized controlled trial of median sternotomy versus anterolateral left thoracotomy on morbidity and health care resource use in patients having off-pump coronary artery bypass surgery: The Sternotomy Versus Thoracotomy (STET) trial. $J$ Thorac Cardiovasc Surg 2013; 146: 306-316. e301-309.

2. Dieberg G, Smart NA, King N. Minimally invasive cardiac surgery: A systematic review and meta-analysis. Int J Cardiol 2016; 223: $554-560$

3. Ruel M, Shariff MA, Lapierre H, Goyal N, Dennie C, Sadel SM, et al. Results of the minimally invasive coronary artery bypass grafting angiographic patency study. J Thorac Cardiovasc Surg 2014; 147: 203-208.

4. Levine GN, Bates ER, Blankenship JC, Bailey SR, Bittl JA, Cercek $\mathrm{B}$, et al. 2011 ACCF/AHA/SCAI Guideline for Percutaneous Coronary Intervention: A report of the American College of Cardiology Foundation/American Heart Association Task
Force on Practice Guidelines and the Society for Cardiovascular Angiography and Interventions. Circulation 2011; 124: e574-e651.

5. Wang XW, Qu C, Huang C, Xiang XY, Lu ZQ. Minimally invasive direct coronary bypass compared with percutaneous coronary intervention for left anterior descending artery disease: A meta-analysis. J Cardiothorac Surg 2016; 11: 125.

6. Blazek S, Rossbach C, Borger MA, Fuernau G, Desch S, Eitel I, et al. Comparison of sirolimus-eluting stenting with minimally invasive bypass surgery for stenosis of the left anterior descending coronary artery: 7-year follow-up of a randomized trial. JACC Cardiovasc Interv 2015; 8: 30-38.

7. Drenth DJ, Veeger NJ, Middel B, Zijlstra F, Boonstra PW Comparison of late (four years) functional health status between percutaneous transluminal angioplasty intervention and offpump left internal mammary artery bypass grafting for isolated high-grade narrowing of the proximal left anterior descending coronary artery. Am J Cardiol 2004; 94: 1414-1417.

8. Cisowski M, Drzewiecka-Gerber A, Ulczok R, Abu Samra R, Drzewiecki J, Guzy M, et al. Primary direct stenting versus endoscopic atraumatic coronary artery bypass surgery in patients with proximal stenosis of the left anterior descending coronary artery: A prospective, randomised study. Kardiol Pol 2004; 61: 253-261; discussion 262-264.

9. Reeves BC, Angelini GD, Bryan AJ, Taylor FC, Cripps T, Spyt $\mathrm{TJ}$, et al. A multi-centre randomised controlled trial of minimally invasive direct coronary bypass grafting versus percutaneous transluminal coronary angioplasty with stenting for proximal stenosis of the left anterior descending coronary artery. Health Technol Assess 2004; 8: 1-43.

10. Hong SJ, Lim DS, Seo HS, Kim YH, Shim WJ, Park CG, et al. Percutaneous coronary intervention with drug-eluting stent implantation vs. minimally invasive direct coronary artery bypass (MIDCAB) in patients with left anterior descending coronary artery stenosis. Catheter Cardiovasc Interv 2005; 64: 75-81.

11. Kim JW, Lim DS, Sun K, Shim WJ, Rho YM. Stenting or MID$\mathrm{CAB}$ using ministernotomy for revascularization of proximal left anterior descending artery? Int J Cardiol 2005; 99: 437-441.

12. Thiele H, Neumann-Schniedewind P, Jacobs S, Boudriot E, Walther T, Mohr FW, et al. Randomized comparison of minimally invasive direct coronary artery bypass surgery versus sirolimuseluting stenting in isolated proximal left anterior descending coronary artery stenosis. J Am Coll Cardiol 2009; 53: 2324-2331.

13. Buccheri D, Piraino D, Andolina G, Cortese B. Understanding and managing in-stent restenosis: A review of clinical data, from pathogenesis to treatment. J Thorac Dis 2016; 8: E1150-E1162.

14. Kipp R, Lehman J, Israel J, Edwards N, Becker T, Raval AN. Patient preferences for coronary artery bypass graft surgery or percutaneous intervention in multivessel coronary artery disease. Catheter Cardiovasc Interv 2013; 82: 212-218.

15. Ohlow MA, Farah A, Kuntze T, Lauer B. Patients' preferences for coronary bypass grafting or staged percutaneous coronary intervention in multi-vessel coronary artery disease. Int $\mathrm{J}$ Clin Pract, doi:10.1111/ijcp.13056.

16. Giambruno V, Jones P, Khaliel F, Chu MW, Teefy P, Sridhar K, et al. Hybrid coronary revascularization versus on-pump coronary artery bypass grafting. Ann Thorac Surg 2018; 105: 1330-1335.

17. Sardar P, Kundu A, Bischoff M, Chatterjee S, Owan T, Nairooz $\mathrm{R}$, et al. Hybrid coronary revascularization versus coronary artery bypass grafting in patients with multivessel coronary artery disease: A meta-analysis. Catheter Cardiovasc Interv 2018; 91: 203-212.

18. Cutlip DE, Windecker S, Mehran R, Boam A, Cohen DJ, van Es GA, et al. Clinical end points in coronary stent trials: A case for standardized definitions. Circulation 2007; 115: 2344-2351.

19. Thygesen K, Alpert JS, White HD, Joint ESC/ACCF/AHA/ WHF Task Force for the Redefinition of Myocardial Infarction, Jaffe AS, Apple FS, Galvani M, et al. Universal definition of myocardial infarction. Circulation 2007; 116: 2634-2653.

20. Park KW, Kang SH, Kang HJ, Koo BK, Park BE, Cha KS, et al. A randomized comparison of platinum chromium-based everolimus-eluting stents versus cobalt chromium-based zotarolimuseluting stents in all-comers receiving percutaneous coronary intervention: HOST-ASSURE (Harmonizing Optimal Strategy For Treatment Of Coronary Artery Stenosis-Safety \& Effectiveness Of Drug-Eluting Stents \& Anti-Platelet Regimen), a randomized, controlled, noninferiority trial. J Am Coll Cardiol 2014; 63: $2805-2816$.

21. Authors/Task Force members, Windecker S, Kolh P, Alfonso F, Collet JP, Cremer J, Falk V, et al. 2014 ESC/EACTS Guidelines on myocardial revascularization: The Task Force on Myocardial Revascularization of the European Society of Cardiology (ESC) 
and the European Association for Cardio-Thoracic Surgery (EACTS) Developed with the special contribution of the European Association of Percutaneous Cardiovascular Interventions (EAPCI). Eur Heart J 2014; 35: 2541-2619.

22. Jaffery Z, Kowalski M, Weaver WD, Khanal S. A meta-analysis of randomized control trials comparing minimally invasive direct coronary bypass grafting versus percutaneous coronary intervention for stenosis of the proximal left anterior descending artery. Eur J Cardiothorac Surg 2007; 31: 691-697.

23. Navarese EP, Kowalewski M, Kandzari D, Lansky A, Gorny B, Koltowski L, et al. First-generation versus second-generation drug-eluting stents in current clinical practice: Updated evidence from a comprehensive meta-analysis of randomised clinical trials comprising 31379 patients. Open Heart 2014; 1: e000064.

24. Radeleff B, Lopez-Benitez R, Stampfl U, Stampfl S, Sommer C, Thierjung $\mathrm{H}$, et al. Paclitaxel-induced arterial wall toxicity and inflammation: Tissue uptake in various dose densities in a minipig model. J Vasc Interv Radiol 2010; 21: 1262-1270.

25. Fan JQ, Du HA, Yin YH, Ling ZY, Wu JJ, Xiao PL, et al. Efficacy and safety of zotarolimus-eluting stents compared with sirolimus-eluting stents in patients undergoing percutaneous coronary interventions: A meta-analysis of randomized controlled trials. Int J Cardiol 2013; 167: 2126-2133.

26. Park KW, Kang SH, Velders MA, Shin DH, Hahn S, Lim WH, et al. Safety and efficacy of everolimus- versus sirolimus-eluting stents: A systematic review and meta-analysis of 11 randomized trials. Am Heart J 2013; 165: 241-250.e244.

27. Park SJ, Ahn JM, Kim YH, Park DW, Yun SC, Lee JY, et al. Trial of everolimus-eluting stents or bypass surgery for coronary disease. $N$ Engl J Med 2015; 372: 1204-1212.

28. Chang M, Lee CW, Ahn JM, Cavalcante R, Sotomi Y, Onuma $\mathrm{Y}$, et al. Comparison of outcome of coronary artery bypass grafting versus drug-eluting stent implantation for non-ST-elevation acute coronary syndrome. Am J Cardiol 2017; 120: 380-386.

29. Serruys PW, Morice MC, Kappetein AP, Colombo A, Holmes DR, Mack MJ, et al. Percutaneous coronary intervention versus coronary-artery bypass grafting for severe coronary artery disease.
N Engl J Med 2009; 360: 961-972.

30. Park KW, Kang SH, Park JJ, Yang HM, Kang HJ, Koo BK, et al Adjunctive cilostazol versus double-dose clopidogrel after drugeluting stent implantation: The HOST-ASSURE randomized trial (Harmonizing Optimal Strategy for Treatment of Coronary Artery Stenosis-Safety \& Effectiveness of Drug-Eluting Stents \& Anti-platelet Regimen). JACC Cardiovasc Interv 2013; 6: $932-$ 942.

31. Wang P, Zhou S, Zhou R, Liu G, Tang P, He J, et al. The effectiveness and safety of triple-antiplatelet treatment based on cilostazol for patients receiving percutaneous coronary intervention: A meta-analysis. Clin Cardiol 2012; 35: 598-604

32. Smith SC Jr, Benjamin EJ, Bonow RO, Braun LT, Creager MA, Franklin BA, et al. AHA/ACCF secondary prevention and risk reduction therapy for patients with coronary and other atherosclerotic vascular disease: 2011 update: A guideline from the American Heart Association and American College of Cardiology Foundation. Circulation 2011; 124: 2458-2473.

33. Vanker EA, Ajayi NO, Lazarus L, Satyapal KS. The intramyocardial left anterior descending artery: Prevalence and surgical considerations in coronary artery bypass grafting. $S$ Afr $J$ Surg 2014; 52: 18-21.

34. Spence PA, Gray LA Jr. New conduits for coronary artery bypass: Great promise for improved outcome from coronary artery surgery. J Ky Med Assoc 1994; 92: 52-58.

35. Armstrong EJ, Feldman DN, Wang TY, Kaltenbach LA, Yeo $\mathrm{KK}$, Wong SC, et al. Clinical presentation, management, and outcomes of angiographically documented early, late, and very late stent thrombosis. JACC Cardiovasc Interv 2012; 5: 131-140.

36. Fuku Y, Kadota K, Amano H, Kubo S, Otsuru S, Habara S, et al. Impact of dual antiplatelet therapy beyond 1 year on clinical outcomes of patients with stent fracture or peri-stent contrast staining after sirolimus-eluting stent implantation. Circ J 2017; 82: $211-217$.

37. Cho MS, Park DW. Stent thrombosis and optimal duration of dual antiplatelet therapy after coronary stenting in contemporary practice. Korean J Intern Med 2017; 32: 769-779. 